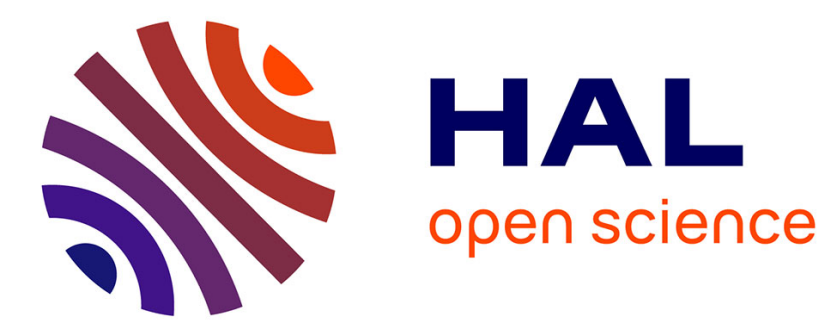

\title{
Aqueous Supramolecular Polymer Formed from an Amphiphilic Perylene Derivative
}

Alix Arnaud, Joël Belleney, François Boué, Laurent Bouteiller, Géraldine Carrot, Véronique Wintgens

\section{- To cite this version:}

Alix Arnaud, Joël Belleney, François Boué, Laurent Bouteiller, Géraldine Carrot, et al.. Aqueous Supramolecular Polymer Formed from an Amphiphilic Perylene Derivative. Angewandte Chemie International Edition, 2004, 43 (13), pp.1718-1721. 10.1002/anie.200353434 · hal-01696744

\section{HAL Id: hal-01696744 https://hal.science/hal-01696744}

Submitted on 29 Aug 2020

HAL is a multi-disciplinary open access archive for the deposit and dissemination of scientific research documents, whether they are published or not. The documents may come from teaching and research institutions in France or abroad, or from public or private research centers.
L'archive ouverte pluridisciplinaire HAL, est destinée au dépôt et à la diffusion de documents scientifiques de niveau recherche, publiés ou non, émanant des établissements d'enseignement et de recherche français ou étrangers, des laboratoires publics ou privés. 


\title{
AQUEOUS SUPRAMOLECULAR POLYMER FORMED BY AN AMPHIPHILIC PERYLENE DERIVATIVE.
}

\author{
Alix ARNAUD, Joël BELLENEY, François BOUE, Laurent BOUTEILLER*, Géraldine \\ CARROT, Véronique WINTGENS.
}

[*] Dr. L. Bouteiller, A. Arnaud,

Laboratoire de Chimie des Polymères, UMR 7610, Université Pierre et Marie Curie

4, place Jussieu, 75252 Paris cedex05, France. Fax: (+33) 144277089

Dr. V. Wintgens

Laboratoire de Recherche sur les Polymères, 2-8 rue Henri Dunant, 94320 Thiais, France

Dr. F. Boué, Dr. G. Carrot

Laboratoire Léon Brillouin, CEA-Saclay, 91191 Gif-sur-Yvette Cedex, France.

\section{Introduction}

Supramolecular polymers are reversible one-dimensional assemblies, driven by dynamic noncovalent intermolecular interactions. ${ }^{\text {"II }}$ Apart from biological systems, such self-assemblies are mostly described in organic and non-polar solvents, relying on hydrogen bonding or metalligand interaction. Interesting material properties have been demonstrated in the case of specific monomers such as ureido-pyrimidones ${ }^{[2]}$ or bis-ureas ${ }^{[3]}$ that can self-organize in very long chains. These materials combine conventional polymer properties with reversibility and responsiveness. It is a challenging objective to expand this innovative theme to aqueous medium. The main drawback of hydrogen bond is its limited strength in polar solvents, and in particular in water. Therefore, other non-covalent interactions should be considered in the aqueous medium. So far, only few synthetic supramolecular polymers have been described in water, mostly relying on aromatic and/or hydrophobic interactions. ${ }^{[4,5,6,7]}$ Moreover, their syntheses are not well suited for large scale preparation and their properties as materials (such as rheology) have never been reported. We designed an amphiphilic molecule (compound 1) affordable in large scale, via easy synthesis and purification (Figure 1). This perylene derivative exhibits a large hydrophobic aromatic core, surrounded by four hydrophilic arms. Such a design should provide one-dimensional assembly in water, through intermolecular $\pi$ stacking and/or hydrophobic interactions. The four hydrophilic arms are expected to hinder side aggregation of such assemblies and to ensure their water-solubility. In this report, we detail the synthesis and the characterization of the supramolecular polymer formed by association of monomer $\mathbf{1}$ in water. 


\section{Results and discussion \\ Synthesis}

The hydrophobic aromatic center is derived from 3,4,9,10-perylenetetracarboxylic dianhydride (PTCA) (Figure 1). PTCA is reacted with an excess of (methoxyethoxy)ethyl iodide and (methoxyethoxy)ethanol, as adapted from literature. ${ }^{\left({ }^{8}\right)}$ Compound $\mathbf{1}$ was obtained as an orange wax (47\% yield, not optimized). Extensive molecular analysis is in full agreement with the structure assigned (see the experimental section in Supporting Information).

\section{Qualitative evidence of self-assembly of compound 1}

In chloroform, compound $\mathbf{1}$ is molecularly dissolved, as concluded from the concentration independence of the absorption and fluorescence spectra (data not shown). In more polar solvents such as ethanol and water, the UV spectra are shifted and their resolution decline with the solvent polarity (Figure 2). This phenomenon is maximized in water, as expected. Figure 3 indicates a clear dependence of the fluorescence spectra versus concentration in water. The band at $480 \mathrm{~nm}$, which can be assigned to the free monomer, disappears and a broader red-shifted band appears when concentration is increased. These results indicate that self-assembly of $\mathbf{1}$ occurs in water.

'H NMR spectra are in total agreement with these observations. In deuterated DMSO and chloroform, spectra of compound 1 (at $10^{-2} \mathrm{~mol} \mathrm{L^{-1 }}$ ) are well resolved. However, at the same concentration in deuterated methanol and even more in water, an upfield shift and a strong broadening of the aromatic signals are observed. This phenomenon is probably related to selfassociation via aromatic stacking. This is further demonstrated by the evolution of the NMR spectra of 1 in deuterated water with increasing concentration (Figure S1). Inner protons $(\beta)$ are the most affected by the self-association, their chemical shifts vary from $7.76 \mathrm{ppm}$ at 1.4 $10^{-6} \mathrm{M}$ to $5.81 \mathrm{ppm}$ at $5.010^{2} \mathrm{M}$ (Figure 4 ).

Finally, the relative viscosity of aqueous solutions increases with the concentration of 1 (Figure S2). This observation agrees with a typical polymeric behavior of $\mathbf{1}$ in water on a macroscopic scale.

\section{Shape of the supramolecular aggregates}

Compound 1 was designed to self-assemble in water in one-dimensional columns by $\pi-\pi$ co facial overlap and hydrophobic interaction. This model had already been proposed but not proved for the self-association of similar perylene derivatives in chloroform. ${ }^{(9)}$ We studied solutions of compound 1 (in deuterated water at $25^{\circ} \mathrm{C}$ ) using small-angle neutron scattering (SANS) to demonstrate the expected monomolecular column structure. Figure 5 shows the product of the intensity $I(q)$ by the scattering vector $q$ for three concentrations in log-log plot. The insert of this figure shows for the three concentrations that the scattered intensity is proportional to the concentration. Therefore, it is reasonable to assume that no inter-object correlations are visible: the signal is proportional to the signal of one single object in this $q$ range. At intermediate scattering vector, the $q I$ product shows a plateau corresponding to a $q^{\prime}$ 
dependence well known as the signature of rod-like objects. However, when $q$ tends towards zero, the $q I$ product increases. This shows a stronger $q$ dependence for $I$, attributed to larger additional aggregates.

A model of infinite rigid rods with circular cross section and a uniform scattering length density profile was used. ${ }^{100}$ Fitting the scattering curves according to equations (1) and (2) provides the characteristics of the fibrillar objects.

$$
\begin{aligned}
& I=\frac{\pi c}{q} \overline{\Delta b}^{2} M_{L}\left[2 \cdot \frac{J_{1}(q r)}{q r}\right]^{2} \\
& (q l)_{q \rightarrow 0}=(q l)_{o} \exp \left(-\frac{r^{2} q^{2}}{4}\right)
\end{aligned}
$$

$c$ is the rod concentration $\left(\mathrm{g} . \mathrm{cm}^{-3}\right), M_{L}$ is the mass per unit length of the rod $\left(\mathrm{g} . \AA^{-1}\right), \overline{\Delta b}$ is its specific contrast (i.e. the difference in density of scattering length between $\mathbf{1}$ and the solvent $\left.\mathrm{D}_{2} \mathrm{O}\right), r$ is the radius of the cross section, and $J_{l}$ is the Bessel function of the first kind.

Figure 5 shows satisfying fits for $q \geq 0.01 \AA$, establishing a constant rod diameter $(2 r=24 \AA)$ over this range of concentration. A $24 \AA$ diameter is coherent with the largest dimension of compound 1 ( $29 \AA$, estimated with Chem3D software). This confirms that the rod is a onedimensional assembly of stacked molecules of $\mathbf{1}$, i.e. a supramolecular polymer of monomer $\mathbf{1}$ in water.

\section{Strength of the association}

A model involving an infinite number of equilibria (Figure 1) can describe the formation of long supramolecular chains. It is reasonable to suppose that the association constant is not influenced by the length of the oligomers larger than dimers."1!I Then, the free monomer concentration $\left(M_{i}\right)$ can be numerically calculated from the mass balance equation :

$$
C_{o}=M_{1}\left(1+\frac{K_{2}}{K}\left(\frac{1}{\left(1-K M_{1}\right)^{2}}-1\right)\right)
$$

where $C_{o}$ is the total concentration, $\mathrm{K}_{2}$ and $\mathrm{K}$ the dimerization and multimerization constants, respectively.

NMR and fluorescence spectroscopies were used to determine these association constants.

By 'H NMR, the upfield shift of the aromatic protons was monitored over a wide range of concentration ( $C_{o}$ varying from $10^{-6} \mathrm{M}$ to $10^{-1} \mathrm{M}$, Figure 4$)$. In the model for stacking, we assign $f_{i}\left(\delta_{1}\right), f_{e}\left(\delta_{c}\right), f_{i}\left(\delta_{i}\right)$, as the mole fractions (and the chemical shifts) of free monomer, molecules at the ends of the stack and molecules within a stack, respectively. Moreover, we assume that $\delta_{\mathrm{c}}=\left(\delta_{1}+\delta_{\mathrm{i}}\right) / 2$. ${ }^{! 1}$ Then, the observed chemical shift is given by:

$$
\delta=f_{1} . \delta_{1}+f_{\mathrm{e}} \cdot\left(\delta_{1}+\delta_{\mathrm{i}}\right) / 2+f_{\mathrm{i}} \cdot \delta_{\mathrm{i}}
$$


According to the two-constant model, and after some mathematical manipulations, we can establish:

$$
\delta=\frac{M_{1}}{C_{o}} \cdot \delta_{1}+2 \cdot \frac{K_{2} \cdot M_{1}^{2}}{C_{o} \cdot\left(1-K \cdot M_{1}\right)^{2}} \cdot \frac{\left(\delta_{1}+\delta_{i}\right)}{2}+\frac{K_{2} \cdot K \cdot M_{1}^{3}}{C_{o} \cdot\left(1-K \cdot M_{1}\right)^{2}} \cdot \delta_{j}
$$

By fluorescence, we monitored the $480 \mathrm{~nm}$ band intensity (normalized by the concentration, $\left.I_{* 8 \delta}\right)$, and determined the free monomer fraction for highly dilute solutions $\left(C_{o}\right.$ varying from $10^{8}$ $\mathrm{M}$ to $10^{-5} \mathrm{M}$ ) with equation (6).

$$
f_{i}=\mathrm{I}_{480} / \mathrm{I}_{\text {o }}
$$

where $I_{o}$ is the monomer normalized fluorescence intensity. (See the Supporting Information for more details).

In a single process, we fitted the experimental chemical shifts $(\delta)$ of the aromatic protons and the experimental values of $f_{i}$ determined by fluorescence, according to equations (5) and (6) respectively. The six adjustable parameters were $\mathrm{K}_{2}, \mathrm{~K}, \delta_{1}{ }^{\alpha}, \delta_{i}^{\alpha}, \delta_{1}{ }^{\beta}$ and $\delta_{i}^{\beta}$. The Figures 4 and 6 display the satisfying fitting curves, whereas Table 1 lists the determined constants.

The large $\mathrm{K}_{2}$ value illustrates the important hydrophobicity of $\mathbf{1}$. Unfortunately, the low $\mathrm{K} / \mathrm{K}_{2}$ value demonstrates an anti-cooperative association process: oligomerization is disfavored versus dimerization. This anti-cooperativity can be the result of electronic effects and/or the steric bulk of the hydrophilic side-chains.. The association constant between two oligomers $\left(\mathrm{K}^{2} / \mathrm{K}_{2}=10^{5} \mathrm{~L} \mathrm{~mol}^{-1}\right)$ can be considered as the most relevant parameter for the association strength. ${ }^{[12]}$ The knowledge of the association constants makes it possible to compute the degree of polymerization of the supramolecular polymer versus concentration (Figure S3). For instance, at a concentration of $20 \mathrm{~g} \mathrm{~L}^{-1}$, the number average degree of polymerization is $D P_{n}=60$. This significant but modest value is in agreement with the limited viscosity measured (Figure S2).

\section{Conclusion}

This paper describes the easy synthesis of an amphiphilic monomer and its ability for selfassociation. Investigations of both the structure and the strength of these assemblies have shown that the design of the monomer was well suited for self-association in polar and protic solvents, especially in water. These assemblies are long monomolecular wires, i.e. aqueous supramolecular polymers. However, the association exhibits an anti-cooperative feature, limiting the material properties. Therefore, improving the association strength is the next stage of this project.

\section{Experimental section}

Synthesis : see the Supporting Information.

\section{Self-assembly:}

Measurements for the self-association were recorded on a Bruker ARX $500 \mathrm{MHz}$ instrument, and very dilute solutions $\left(10^{-5} \mathrm{M}\right.$ and $\left.10^{-6} \mathrm{M}\right)$ were analyzed on a Varian $600 \mathrm{MHz}$ Innova with 
a cryoprobe. UV-vis spectroscopy was performed on a Varian Cary $1 \mathrm{G}$ spectrometer and fluorescence measurements were carried out on a LSM Aminco 8100 fluorimeter (LRP, Thiais, France). SANS experiments were performed on PACE and PAXY instruments at the LLB (Saclay, France).

Acknowlegements: Muriel Delepierre from the Unité de Résonance Magnétique Nucléaire des Biomolécules at the Pasteur Institut (Paris, France) is acknowledged for the high dilution NMR measurements.

\section{References}

[1] a) N. Zimmerman, J. S. Moore, S. C. Zimmerman, Chem. Ind. 1998, 604-610. b) Supramolecular polymers (Ed. A. Ciferri), Marcel Dekker, Inc., New York, 2000. c) L. Brunsveld, B. J. B. Folmer, E.W.Meijer, R.P.Sijbesma, Chem.Rev. 2001, 101, 4071-4097. d)

A. Ciferri, J. Macromol. Sci., Polym. Rev. 2003, C43, 271-322.

[2] R. P. Sijbesma, F. H. Beijer, L. Brunsveld, B. J. B. Folmer, J. H. K. K. Hirschberg, R. F. M. Lange, J. K. L. Lowe, E.W.Meijer, Science 1997, 278, 1601-1604.

[3] F. Lortie, S. Boileau, L. Bouteiller, C. Chassenieux, B. Demé, G. Ducouret, M. Jalabert, F. Lauprêtre, P. Terech, Langmuir 2002, 18, 7218-7222.

[4] a) L. Brunsveld, J. A. J. M. Vekemans, B. G. G. Lohmeijer, E. W. Meijer, Chem. Comm. 2000, 2305-2306. b) L. Brunsveld, J. A. J. M. Vekemans, J. H. K. K. Hirschberg, R. P. Sijbesma, E. W. Meijer, Proc. Natl. Acad. Sci. U.S.A. 2002, 99, 4977-4982.

[5] A. Harada, Y. Kawaguchi, T. Hoshino, J. Inclusion Phenom. Macrocyclic Chem. 2001, $41,115-121$.

[6] N. Boden, R. J. Bushby, C. Hardy, F. Sixl, Chem. Phys. Lett. 1986, 123, 359-364.

[7] J. H. Fuhrhop, C. Demoulin, C. Boettcher, J. König, U. Siggel, J. Am. Chem. Soc. 1992, $114,4159-4165$.

[8] I. Seguy, P. Jolinat, P. Destruel, R. Mamy, H. Allouchi, C. Courseille, M. Cotrait, H. Block, ChemPhysChem. 2001, 7, 448-452.

[9] W. Wang, J. J. Han, L. Q. Wang, L. S. Li, W. J. Shaw, A. D. Q. Li, Nano. Lett. 2003, 3, 455-458.

[10] P. Terech, A. Coutin, Langmuir 1999, 15, 5513-5525.

[11] R. B. Martin, Chem. Rev. 1996, 96, 3043-3064.

[12] V. Simic, L. Bouteiller, M. Jalabert, J. Am. Chem. Soc. 2003, 125, 13148-13154 


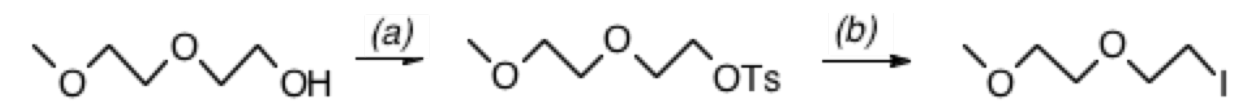<smiles>COCCOCCOC</smiles>

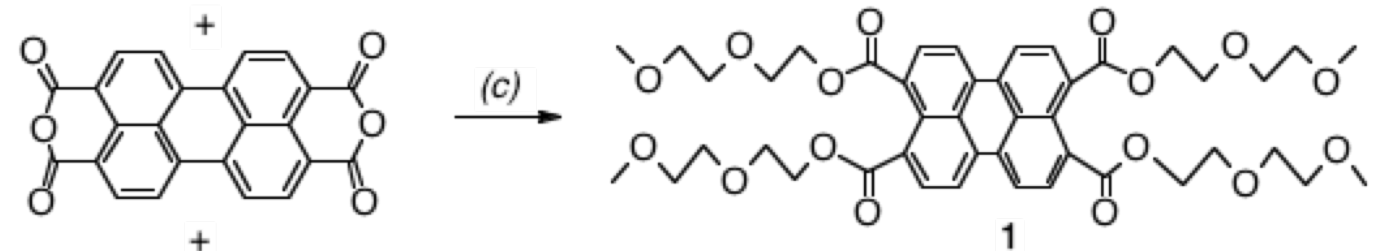<smiles>COCCOCCO</smiles>

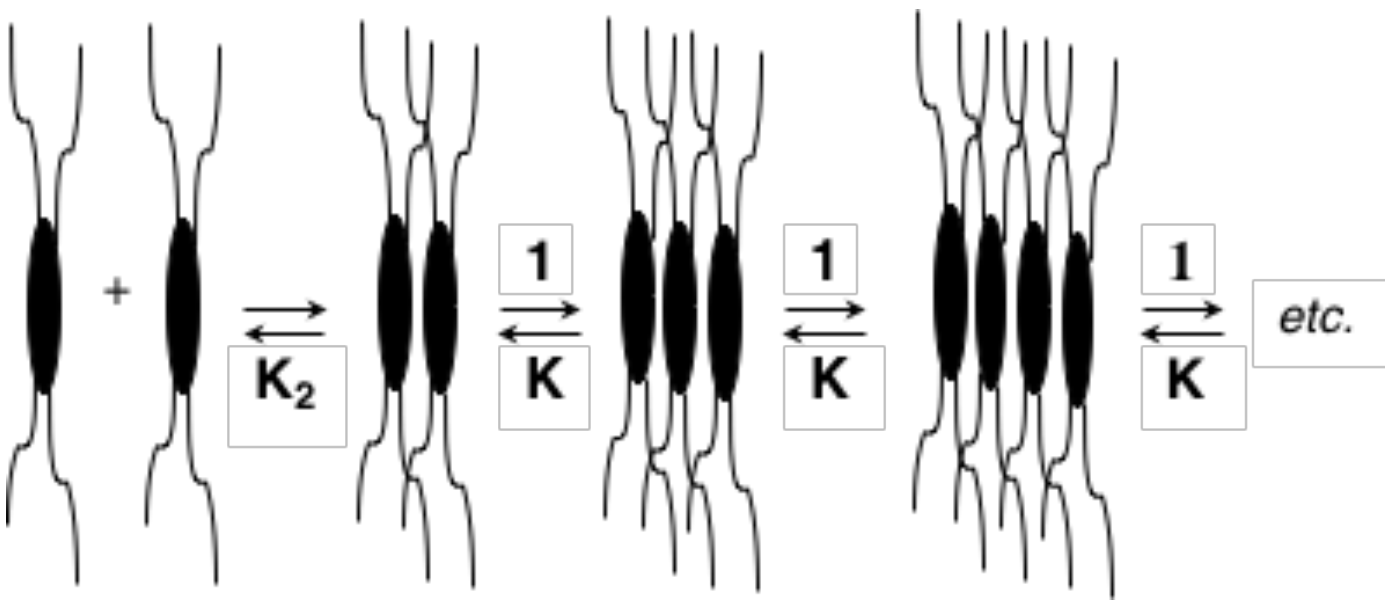

Figure 1: Synthesis and association schemes of compound 1. Conditions: $a$ ) $\mathrm{CH}_{3} \mathrm{C}_{6} \mathrm{H}_{4} \mathrm{SO}_{2} \mathrm{Cl} / \mathrm{NaOH} /$ water/THF, $0-5^{\circ} \mathrm{C}, 96 \%$; b) NaI/ acetone, RT, $73 \%$ c) $\mathrm{K}_{2} \mathrm{CO}_{3}, 70^{\circ} \mathrm{C}$, $47 \%$.

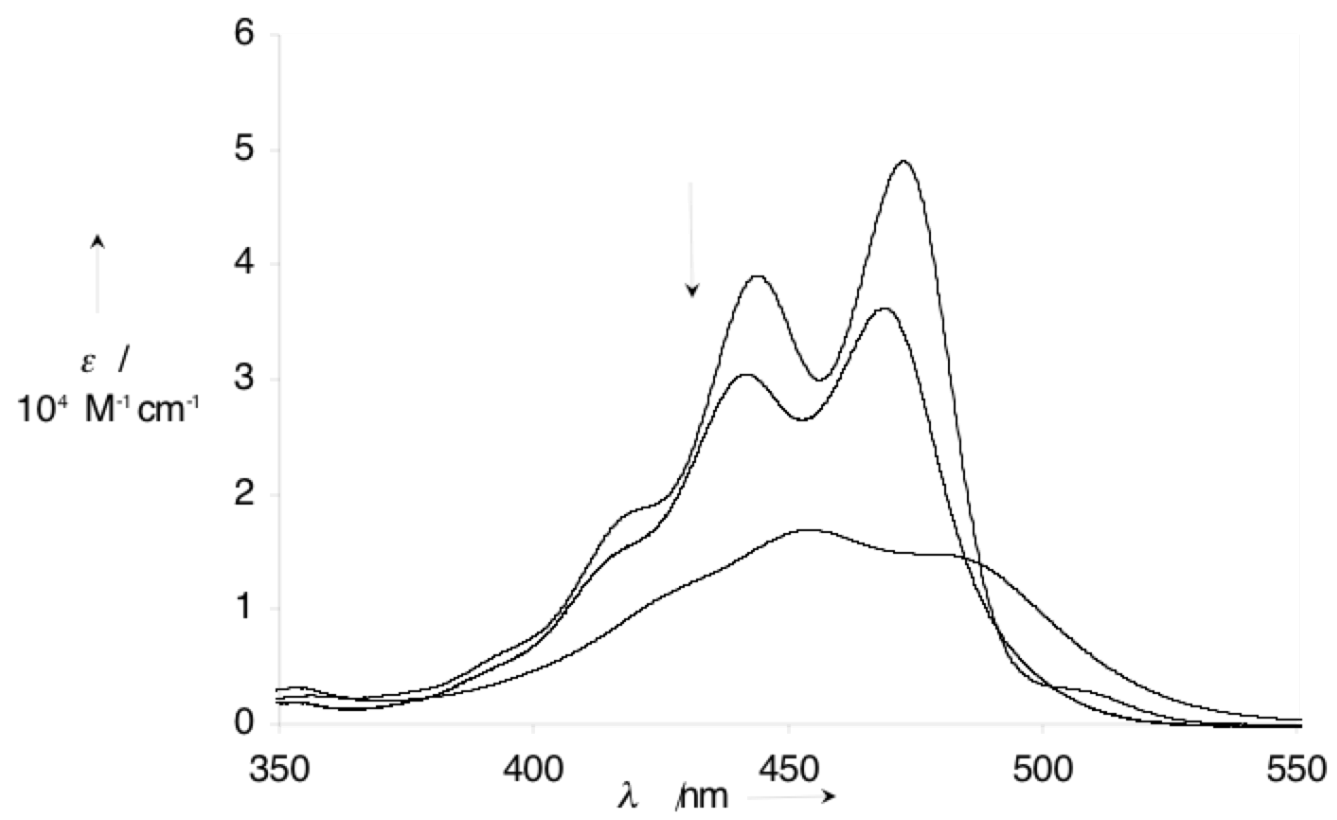

Figure 2: Normalized UV-vis. spectra of solutions of $\mathbf{1}\left(10^{4} \mathrm{M}\right)$, in several solvents. Arrows indicate the direction of change with increasing solvent polarity (-: chloroform, $\triangle$ : ethanol, o: water). 


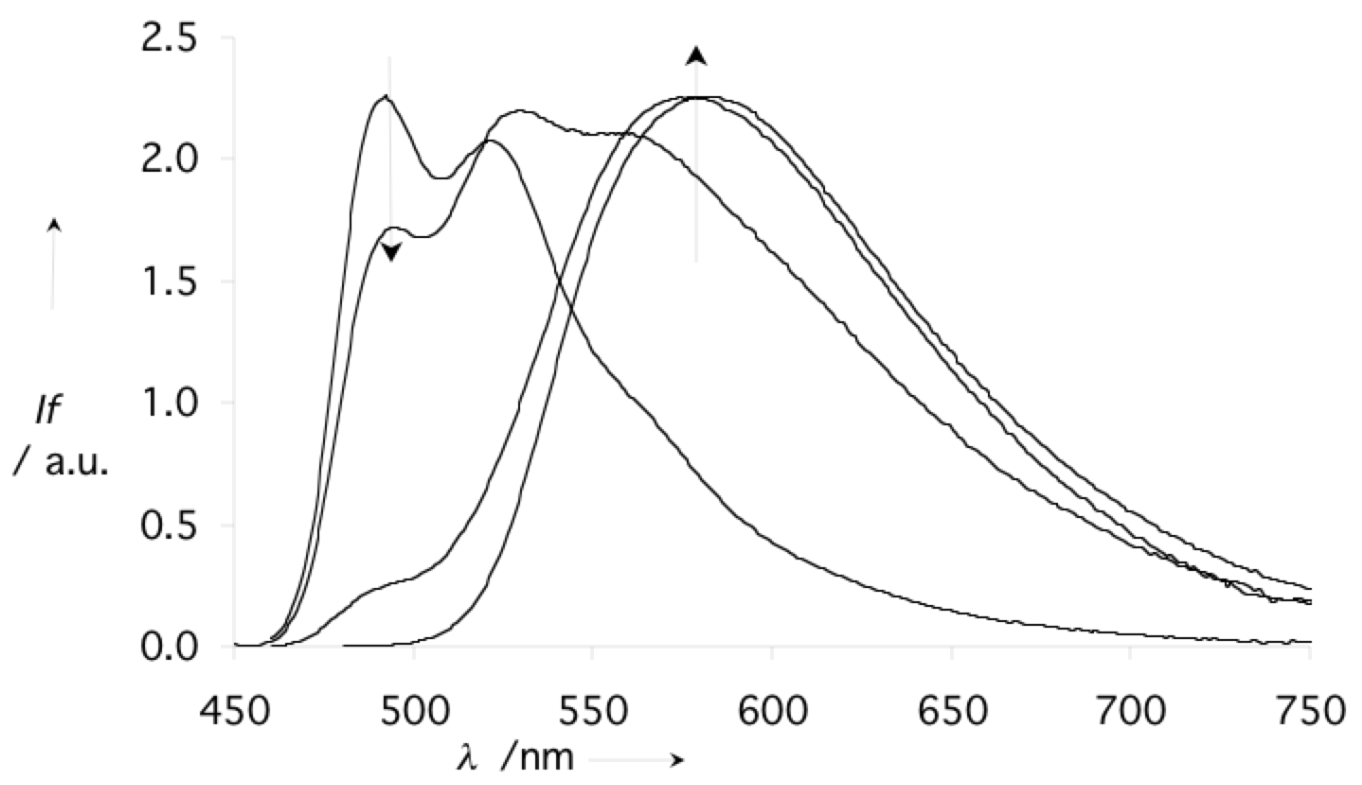

Figure 3: Fluorescence spectra of $\mathbf{1}$ in water, at $25^{\circ} \mathrm{C}\left(-: 410^{-} \mathrm{M}, \mathrm{o}: 10^{-} \mathrm{M},+: 10^{4} \mathrm{M}, \diamond: 10^{2} \mathrm{M}\right)$. Excitation at $425 \mathrm{~nm}$. Arrows indicate the direction of change with increasing concentration.

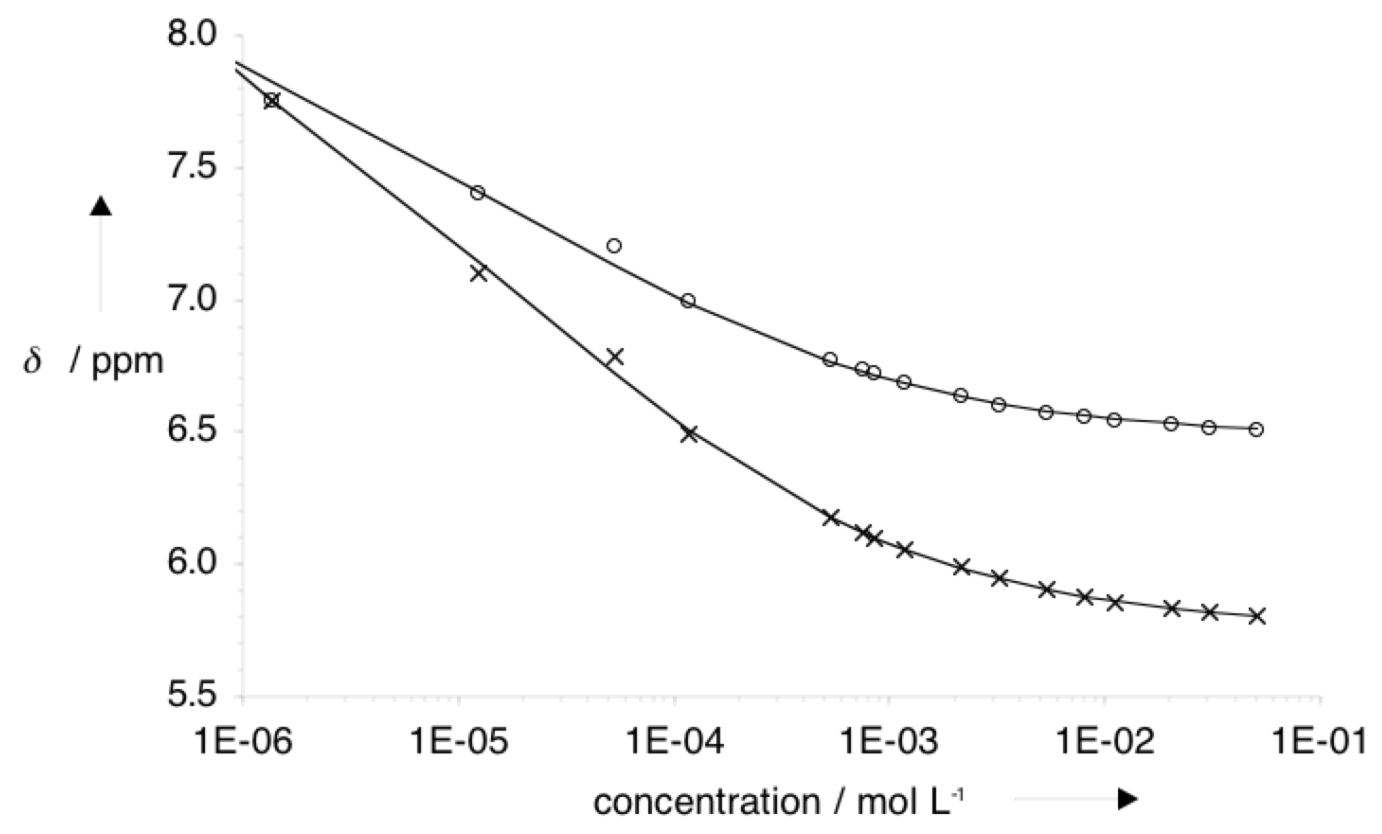

Figure 4: 'H NMR chemical shifts of $\mathbf{1}$ in $\mathrm{D}_{2} \mathrm{O}$ solutions, versus concentration, at $25^{\circ} \mathrm{C}$. (o) : aromatic proton $\alpha ;(\times)$ : aromatic protons $\beta$ (See Figure 1). Curves were calculated according to equation (5), with the values of the association constants reported in Table 1 and $\delta_{1}{ }^{\beta}=9.27$ ppm, $\delta_{i}^{\beta}=5.76 \mathrm{ppm}, \delta_{1}^{\alpha}=8.19 \mathrm{ppm}$ and $\delta_{i}^{\alpha}=6.47 \mathrm{ppm}$. 


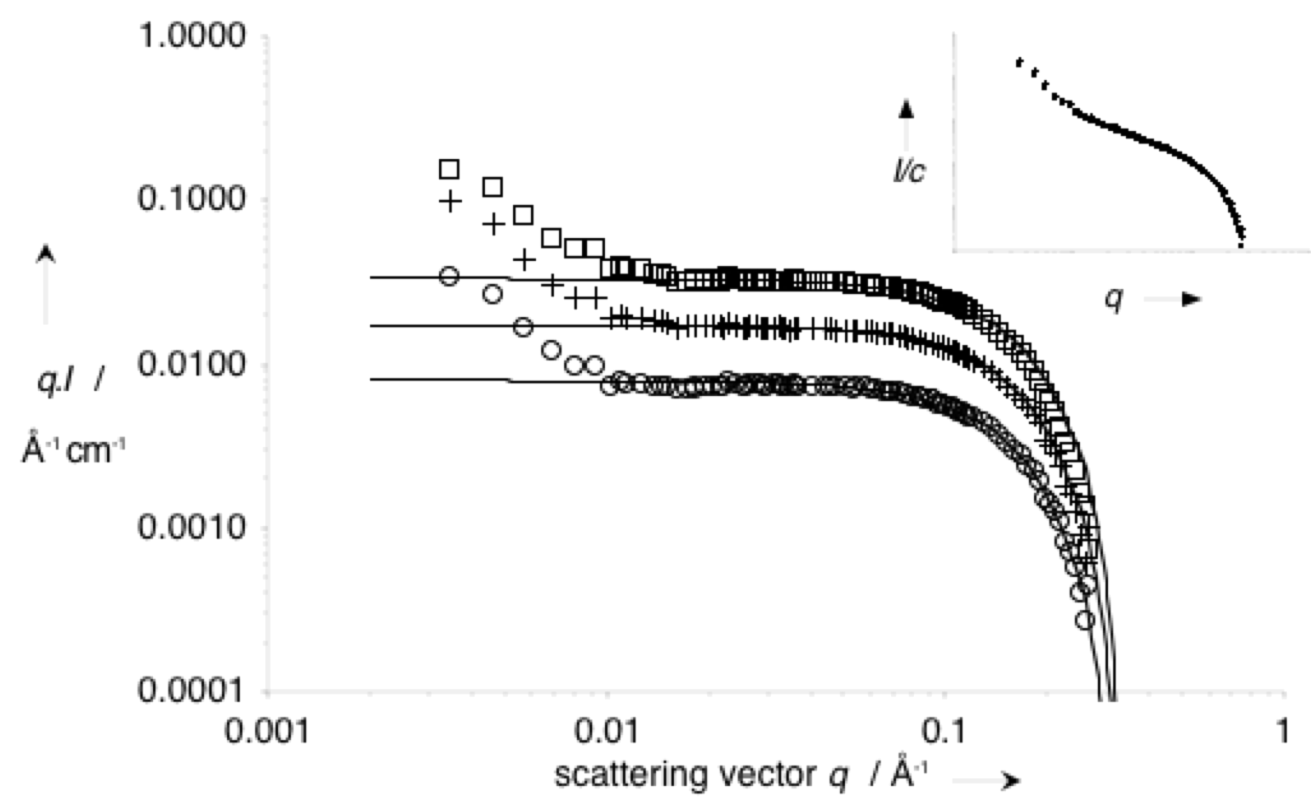

Figure 5: SANS data for solutions of compound 1 in $\mathrm{D}_{2} \mathrm{O}$, at $0.5 \%(\mathrm{o}), 1 \%(+)$ and $2 \%($ ) at $25^{\circ} \mathrm{C}$. Curves were fitted according to equation (1). Insert: $I / c$ vs. $q$ for the three concentrations.

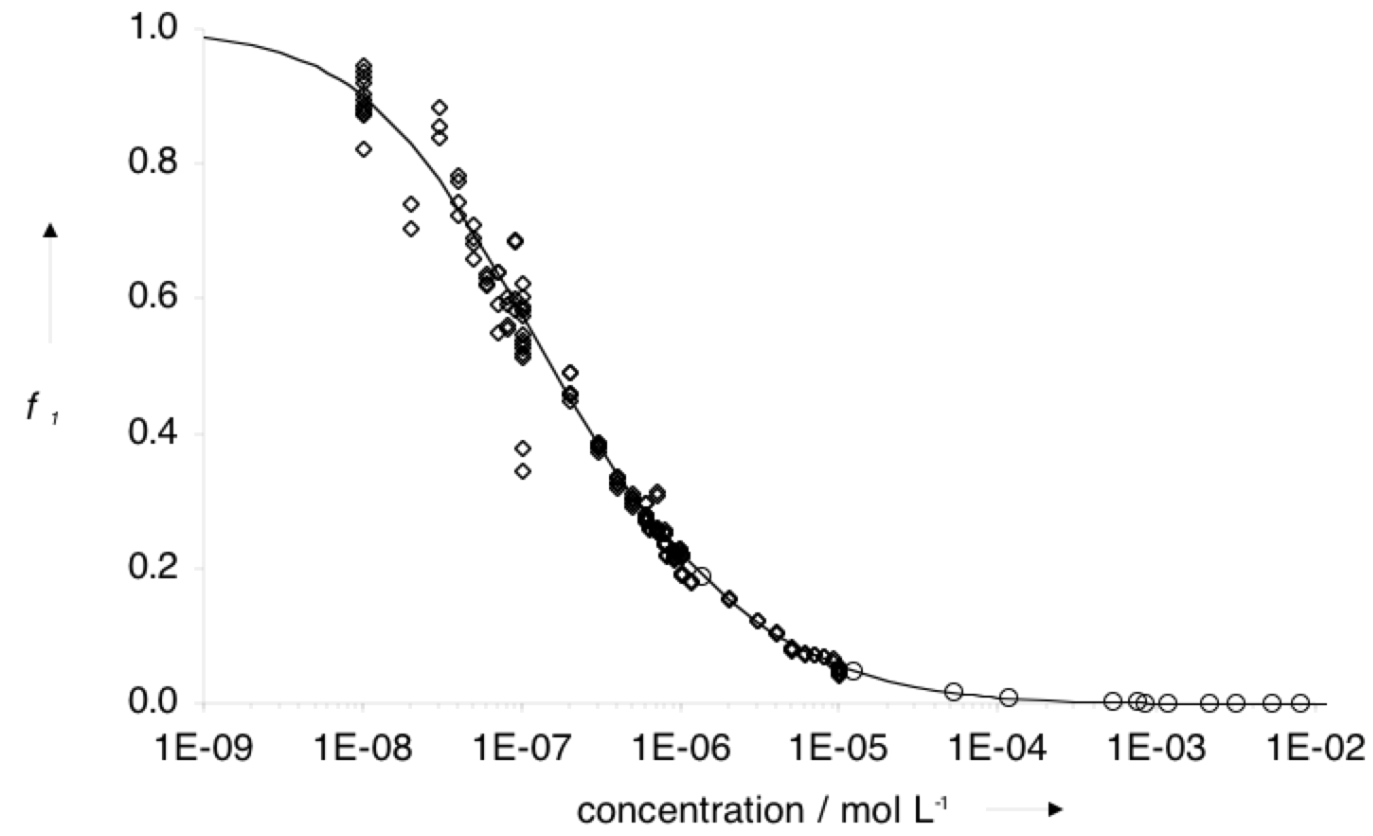

Figure 6: Fraction of free monomer $1\left(f_{i}\right)$, versus concentration in water, at $25^{\circ} \mathrm{C}$. Experimental fluorescence $(\diamond)$ and NMR (o) data, fitted simultaneously with a two-constant model (-). The values of the constants are reported in Table 1. 
Table 1. Characteristics of association of monomer $\mathbf{1}$ in water, at room temperature.

\begin{tabular}{|c|c|c|c|}
\hline $\mathbf{K}_{2}^{\text {[i] }}$ & $\mathbf{K}^{[i 1}$ & $\mathbf{K} / \mathbf{K}_{2}^{\text {[ii] }}$ & $\mathbf{K}^{2} / \mathbf{K}_{2}^{\text {[iii) }}$ \\
\hline $6( \pm 1.5) .10^{6}$ & $8( \pm 1) .10^{5}$ & $0.13 \pm 0.03$ & $1( \pm 0.1) .10$ \\
\hline
\end{tabular}

[i] Dimerization $\left(\mathrm{K}_{2}\right)$ and multimerization $(\mathrm{K})$ constants, in L.mol ${ }^{-1}$.

[ii] Measure of the cooperativity along the supramolecular chain.

[iii] Association constant between oligomers, in $\mathrm{L} \mathrm{mol}^{-1} \cdot{ }^{[12]}$

\section{Text for the table of contents:}

Linear reversible polymers have been prepared by self-assembly of an amphiphilic perylene derivative in water. Aromatic staking and hydrophobic interactions are the driving forces of this system. The structure of the assemblies has been elucidated by SANS, and the association strength determined by NMR and fluorescence spectroscopies.

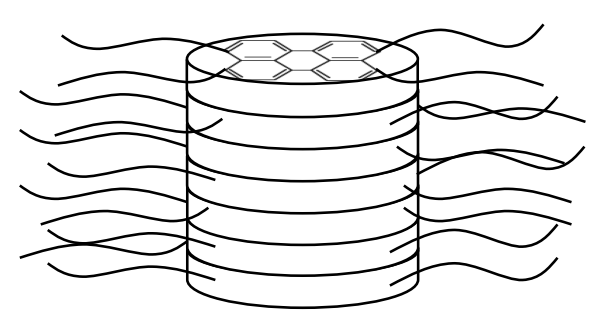

Keywords : self-assembly, pi-interaction, supramolecular, water-soluble, perylene. 